endoscopy. The presence of eye signs should improve compliance with bowel examination.

This study shows that hypertrophy of the retinal pigment epithelium is a valuable clinical sign of familial adenomatous polyposis, although confirmatory studies are required to establish the sensitivity and specificity of this finding. If cases of familial adenomatous polyposis of early onset can reliably be identified by examination of the eye paediatric management may be amended; invasive bowel examination could be delayed until after adolescence in children who do not have congenital hypertrophy of the retinal pigment epithelium.

PDC is supported by the Northern Regional Research
Committee and the Imperial Cancer Research Fund. We thank the surgeons in the Northern region for their cooperation.

1 Blair NP, Trempe CL. Hypertrophy of the retinal pigment epithelium associated with Gardner's syndrome. Am F Ophthalmol 1980;90:661-7.

2 Traboulsi EI, Krush AJ, Gardner EJ, et al. Prevalence and importance of pigmented ocular fundus lesions in Gardner's syndrome. $N$ Engl f Med 1987;316:661-7.

Diaz-Lopez M, Menezo JL. Congenital hypertrophy of the retinal pigmen epithelium in familial adenomatous polyposis. Arch Ophthalmol 1988;106 $412-3$

4 Traboulsi EI, Maumenee IH, Krush AJ, et al. Pigmented ocular fundus lesions in the inherited gastrointestinal polyposis syndromes and in hereditary nonpoly. the inherited gastrointestinal polyposis syndromes and in

5 Bodmer WF, Bailey CJ, Bodmer J, et al. Localisation of the gene for familial adenomatous polvposis on chromosome 5. Nature 1987;328:614-6.

Accepted 22 November 1988

\title{
Assessment of DNA fingerprinting for rapid identification of outbreaks of systemic candidiasis
}

Department of Medical Microbiology, St

Bartholomew's Hospital, London EC1A 7BE

Ruth Matthews, MD,

Wellcome senior research fellow

James Burnie, MD, consultant

bacteriologist

Correspondence to:

Dr Matthews.

BrMed F 1989;298:354-7

\author{
Ruth Matthews, James Burnie
}

\begin{abstract}
DNA fingerprinting was assessed as an improved typing system for Candida albicans aimed at speeding the implementation of cross infection control measures in outbreaks of systemic candidiasis. The study was carried out with 45 previously characterised isolates from five different outbreaks and with 96 unrelated isolates from a mixed control population. Sixteen different genotypes were produced. Results were obtainable within days, reproducibility was high, and there was good discrimination among different outbreaks.

Compared with existing typing systems DNA fingerprinting provides a robust system that may be used rapidly to identify outbreaks of nosocomial candidiasis in laboratories with no specialist skill in typing $C$ albicans.
\end{abstract}

\section{Introduction}

Mortality from systemic candidiasis is over $70 \%$, so early identification of outbreaks is particularly important. Prompt implementation of barrier nursing and handwashing with fungicidals prevents deaths. ${ }^{2}$ Such cross infection control measures are expensive and time consuming, so that it is important to be able to distinguish an outbreak from a cluster of unrelated cases due to endogenous infections. In an outbreak a single epidemic strain causes cross infection among patients. This requires a fast, reliable typing system. Existing typing systems are slow and need to be used in combination. ${ }^{3.5}$ The setting up of a DNA diagnostic service for inherited disorders has recently been described, ${ }^{6}$ and we decided to investigate the potential of DNA fingerprinting in the early identification of outbreaks of nosocomial candidiasis. Isolates were examined from five outbreaks affecting 37 patients, 27 of whom died.

\section{Materials and methods}

Isolates-We examined 45 isolates from five outbreaks of systemic candidiasis and 94 control isolates from 51 patients with oral thrush, 33 patients with vaginal candidiasis, and 10 patients with candidal septicaemia. Two Candida albicans type strainsnamely, National Collection of Type Cultures (NCTC) 3153 (serotype A) and NCTC 3156 (serotype B) - were also typed. Identification as $C$ albicans was based on a positive germ tube test result and the pattern of sugar reactions on the yeast API 20C system (API Laboratories, Basingstoke).

DNA fingerprinting - After overnight growth in $2 \%$ glucose broth yeasts were harvested, washed in $1 \mathrm{M}$ sorbitol, and incubated for 30 minutes at $30^{\circ} \mathrm{C}$ in $1 \mathrm{ml}$ $1 \cdot 2 \mathrm{M}$ sorbitol and $0 \cdot 1 \mathrm{M}$ edetic acid $\mathrm{pH} 7 \cdot 5$ containing $1 \mu \mathrm{l} 2$-mercaptoethanol and $0 \cdot 1 \mathrm{mg}$ zymolase. The resultant spheroplasts, after resuspension in $0.5 \mathrm{ml}$ $50 \mathrm{mM}$ edetic acid pH $8 \cdot 5$, were lysed by adding sodium dodecyl sulphate $(2 \mathrm{~g} / \mathrm{l})$. Diethyl pyrocarbonate $(30 \mu \mathrm{l})$ was added and the whole incubated at $70^{\circ} \mathrm{C}$ for 30 minutes, followed by $50 \mu \mathrm{l} 5 \mathrm{M}$ potassium acetate and incubation at $0^{\circ} \mathrm{C}$ for 30 minutes. After centrifugation the supernatant was decanted into $1 \mathrm{ml}$ cold ethanol to precipitate nucleic acid. This was washed, dried, and suspended in $100 \mu \mathrm{TE}(10 \mathrm{mM}$ trometamol (TRIS) hydrochloride, $1 \mathrm{mM}$ edetic acid $\mathrm{pH} 7.5$ ) containing $10 \mu \mathrm{g}$ deoxyribonuclease free ribonuclease at $37^{\circ} \mathrm{C}$ for one hour to remove RNA. DNA was precipitated with ethanol, suspended in $85 \mu \mathrm{T} \mathrm{TE}$, and digested to completion with an excess $(200 \mathrm{U})$ of EcoRI restriction endonuclease. Digests were run on a horizontal $0 \cdot 8 \%$ agarose gel together with Hind III digested $\lambda$ and Hind III/EcoRI digested $\lambda$ as size markers.

Typing outbreak isolates - Isolates had been characterised by pre-existing typing systems. Isolates from the first outbreak ${ }^{3}$ (at The London Hospital) were serotyped, ${ }^{8}$ biotyped, ${ }^{9}$ morphotyped, ${ }^{10}$ and antigenically fingerprinted by probing immunoblots of each isolate with rabbit candidal antiserum. $\mathrm{A}$ combination of morphotyping and immunoblot fingerprinting was used to identify outbreaks in the intensive care unit at Queen Elizabeth Hospital, Birmingham; the dialysis unit at St Helier Hospital, Carshalton; King's College Hospital neonatal unit; and a second outbreak in the intensive care unit at The London Hospital. ${ }^{4}$

\section{Results}

Reproducibility was high, and all isolates were typable within 48 hours. Sixteen different types were recognised on the basis of variations in six intensive bands at $6 \mathrm{~kb}, 5 \cdot 1 \mathrm{~kb}, 4 \cdot 2 \mathrm{~kb}, 3.7 \mathrm{~kb}, 2.5 \mathrm{~kb}$, and $1.9 \mathrm{~kb}$ (table I; figs 1 and 2). Multiple bands sometimes occurred at $6-7 \mathrm{~kb}$ or $2 \cdot 3-2 \cdot 7 \mathrm{~kb}$. DNA type 2 predominated among control isolates, accounting 
for $59(63 \%)$ of these (table II). Types 1 and 7 were similar to type 2 but showed consistent reproducible differences in bands in the region of $2.5 \mathrm{~kb}$ and $3.7 \mathrm{~kb}$ respectively. The second commonest was type $6(n=6$; 6\%). Serotype A NCTC strain 3153 gave a type 1 fingerprint and serotype B NCTC strain 3156 a type 4 fingerprint.

\section{FIRST LONDON HOSPITAL OUTBREAK}

Fingerprinting systemic isolates from the first London Hospital outbreak confirmed the occurrence of an outbreak due to an unusual DNA type, designated type 14 (table III). It had a double band at $2 \cdot 3-2 \cdot 4 \mathrm{~kb}$, and there was also a band at $1.9 \mathrm{~kb}$. This three band combination was pathognomonic of the outbreak strain, which could easily be distinguished from non-outbreak strains in the unit (fig 3).

The outbreak strain (DNA type 14, immunoblot type 1, morphotype $\mathrm{Al}$, serotype $\mathrm{A}$, biotype $055 / 057 / 157$ ) systemically infected 11 patients in the unit (table III). Two patients (cases 9 and 13) had proved systemic candidiasis before admission to the intensive care unit. They had different immunoblot fingerprints and different serotypes from the original outbreak strain, and in case 9 the biotype was 117. The

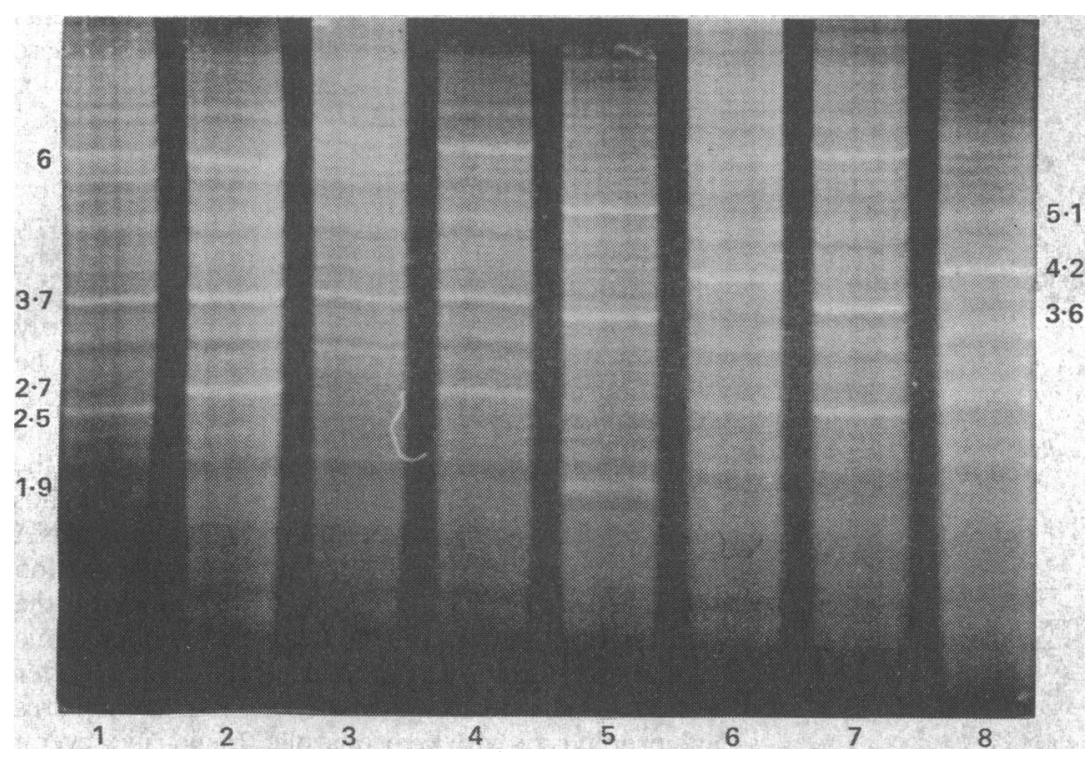

FIG 1-Electrophoretic patterins of DNA types. Tracks 1-8 represent DNA types 1-8 as defined in table I. DNA type 2 responsible for outbreak at King's College Hospital, London; DNA type 4 responsible for outbreak at Queen Elizabeth Hospital, Birmingham. Fragment size given in kb

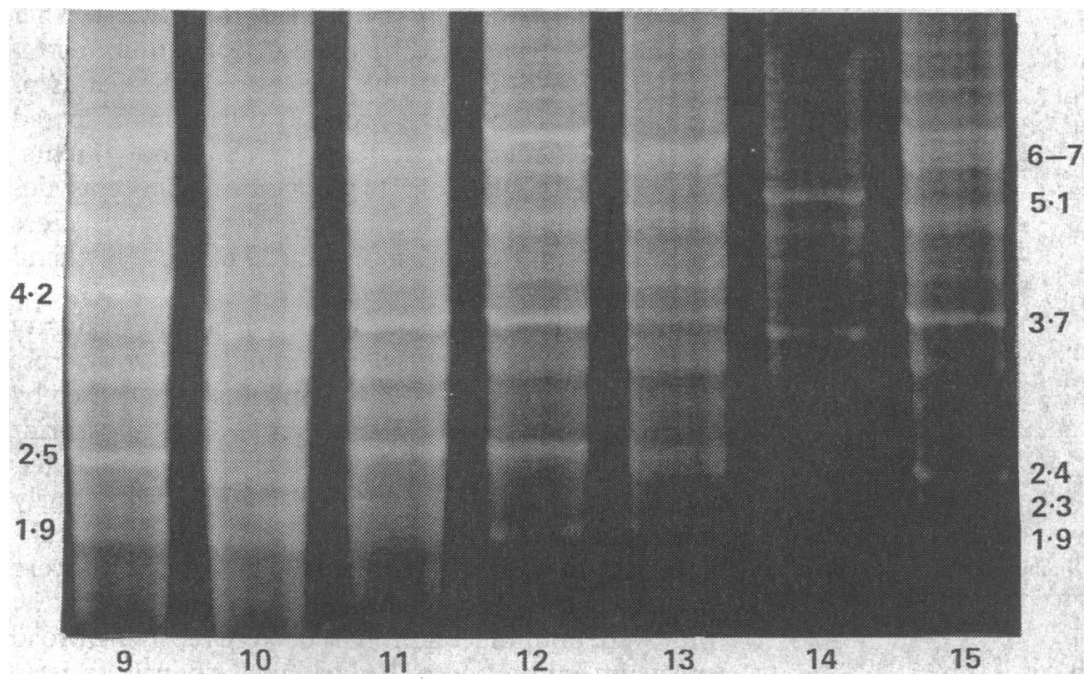

FIG 2-Electrophoretic patterns of DNA types. Track 9 represents DNA type 9. Tracks 10 and 13 represen isolates from St Helier Hospital outbreak (DNA type 10). Track 11 represents DNA type 11, track 12 DNA type 12, track 14 DNA type 13, and track 15 DNA type 14. DNA types defined in table I. Fragment size given in $k b$
TABLE I - Details of 16 DNA types recognised

\begin{tabular}{ccccccc}
\hline & \multicolumn{7}{c}{ DNA bands (kb) } \\
\cline { 2 - 7 } Type No & 6 & $5 \cdot 1$ & $4 \cdot 2$ & $3 \cdot 7$ & $2 \cdot 5$ & $1 \cdot 9$ \\
\hline 1 & + & - & - & + & + & - \\
2 & + & - & - & + & $+{ }^{\star}$ & - \\
3 & - & - & - & + & - & - \\
4 & ++ & - & - & + & $+\star$ & - \\
5 & - & + & - & $+\neq$ & - & + \\
6 & + & - & + & - & + & - \\
7 & + & - & - & $+\neq$ & + & - \\
8 & TB & - & + & - & DB & - \\
9 & TB & - & + & - & + & + \\
10 & DB & - & - & + & DB & + \\
11 & DB & - & - & + & + & - \\
12 & TB & - & - & + & + & + \\
13 & - & + & - & $+\neq$ & - & - \\
14 & TB & - & - & + & DB $\$$ & + \\
15 & DB & - & - & + & + & - \\
16 & + & + & + & + & DB & -
\end{tabular}

$+-=$ Present, absent.

$\mathrm{TB}=$ Triple band at $6-7 \mathrm{~kb}$.

$\mathrm{DB}=$ Double band at $6-7 \mathrm{~kb}$ or $2 \cdot 5 \cdot 2 \cdot 7 \mathrm{~kb}(2 \cdot 3-2 \cdot 4 \mathrm{~kb}$ in type 14$)$

$\star=$ Runs at $2 \cdot 7 \mathrm{~kb}$.

$\star=$ Runs at $2.7 \mathrm{~kb}$.
$t=$ Runs at $6.3 \mathrm{~kb}$.

$t=$ Runs at $6.3 \mathrm{~kb}$

$q=$ Runs at $3 \cdot 6 \mathrm{~kb}$.
$\delta=$ Runs at $2 \cdot 3-2 \cdot 4 \mathrm{~kb}$

TABLE II-Distribution of DNA types among 33 vaginal isolates, 51 oral isolates, and 10 systemic isolates

\begin{tabular}{|c|c|c|c|c|}
\hline \multirow[b]{2}{*}{ DNA type } & \multicolumn{3}{|c|}{ Source of isolate } & \multirow{2}{*}{$\begin{array}{l}\text { Total No o } \\
\text { isolates }\end{array}$} \\
\hline & Vagina & Mouth & Blood culture & \\
\hline 1 & 2 & 1 & & 3 \\
\hline 2 & 21 & 31 & 7 & 59 \\
\hline 3 & & & & 0 \\
\hline 4 & 1 & & 1 & 2 \\
\hline 5 & & 3 & & 3 \\
\hline 6 & 1 & 4 & 1 & 6 \\
\hline 7 & 3 & & & 3 \\
\hline 8 & & 2 & & 2 \\
\hline 9 & 3 & 2 & & 5 \\
\hline 10 & 1 & & & 1 \\
\hline 11 & 1 & 2 & & 3 \\
\hline 12 & & 1 & & 1 \\
\hline 13 & & 1 & & i \\
\hline 14 & & 2 & 1 & 3 \\
\hline 15 & & & & 0 \\
\hline 16 & & 2 & & 2 \\
\hline
\end{tabular}

DNA fingerprint from these two cases was type 2, clearly distinct from the outbreak strain. In cases 14-16 systemic candidiasis occurred after antifungal chemoprophylaxis was begun with ketoconazole and was caused by isolates of DNA types 2,6, and 15. Cross infection control measures and prophylaxis with ketoconazole therefore broke the cycle of infection due to the outbreak strain, type 14 .

The degree of discrimination of DNA fingerprinting was far higher than with any of the other typing systems applied to this outbreak. When applied to isolates from eight colonised patients and two nurses, who were previously thought to have been infected with the outbreak strain because they had the same morphotype, serotype, and biotype (A1, A, $057 / 157 / 055)$, it was found that only four subjects were colonised with DNA type 14 (table III).

\section{SUBSEQUENT OUTBREAKS}

The second outbreak at The London Hospital was due to a different strain of DNA type 16 and immunoblot fingerprint type 17 (table IV). Isolates from the outbreaks at St Helier Hospital, Queen Elizabeth Hospital, and the second London Hospital outbreak were immunoblot type 17 or $17 \mathrm{a}$, whereas DNA typing clearly distinguished among these outbreaks, giving types 10,4 , and 16 respectively. Isolates from King's College Hospital were DNA type 2 and immunoblot type 2 and therefore indistinguishable from the commonest type strain, which was DNA and immunoblot type 2 . The King's College episode probably was due to cross infection, as 
all isolates had an unusual morphotype, A3, but this was unstable and on retyping became the much commoner Al.

\section{Discussion}

DNA fingerprinting is a substantial advance in the rapid identification of outbreaks of infection. In this series all isolates were typable, results were highly reproducible, and they were available within a few days. Only when a suspected outbreak fingerprinted as DNA type 2 was it necessary to use additional typing systems, type 2 being common among non-outbreak isolates. Other DNA types accounted for $6 \%$ or fewer of control isolates. The technique can be carried out in

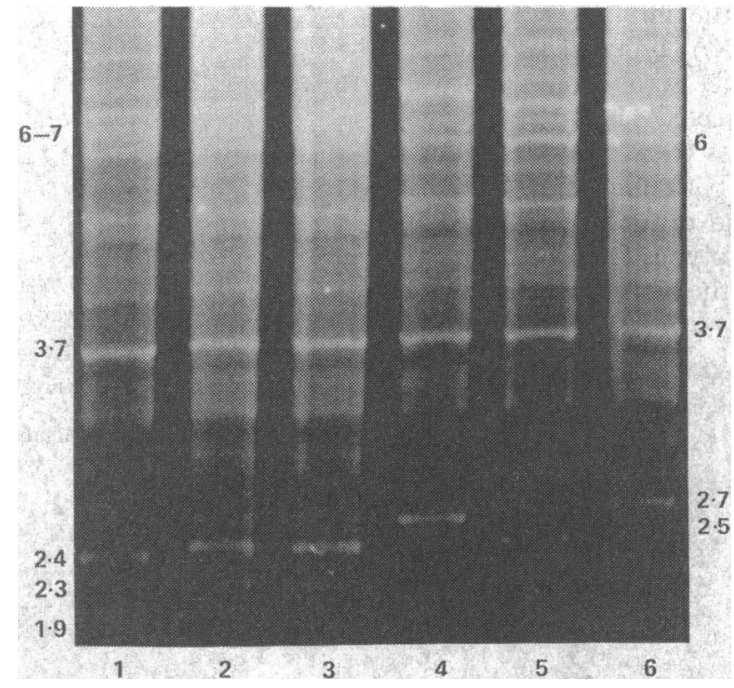

FIG 3-Electrophoretic patterns of DNA types. Tracks 1, 2, 3, and 5 represent isolates from first London Hospital outbreak (DNA type 14). Tracks 4 (DNA type 11) and 6 (DNA type 2) represent isolates from two colonised patients taken at time of outbreak

TABLE III - Typing results of isolates from 16 systemic cases and 10 colonised patients and nurses (cases 17-26) from first London Hospital outbreak

\begin{tabular}{|c|c|c|c|c|c|c|}
\hline Case No & Site & DNA type & Immunoblot type & Morphotype & Serotype & Biotype \\
\hline 1 & Blood culture & 14 & 1 & Al & A & 055 \\
\hline 2 & Blood culture & 14 & 1 & $\mathrm{Al}$ & A & 055 \\
\hline 3 & Blood culture & 14 & 1 & A1 & A & 157 \\
\hline 4 & Laparotomy & & & Not available & & \\
\hline 5 & Lung at necropsy & 14 & 1 & A1 & A & 057 \\
\hline 6 & Blood culture & 14 & 1 & Al & A & 157 \\
\hline 7 & Blood culture & 14 & 1 & $\mathrm{Al}$ & A & 157 \\
\hline & Blood culture & 14 & $i$ & $\mathrm{Al}$ & A & 157 \\
\hline 8 & $\left\{\begin{array}{l}\text { Urine } \\
\text { Uris }\end{array}\right.$ & 14 & i & $\mathrm{Al}$ & $\mathrm{A}$ & 057 \\
\hline 9 & Necropsy tissue & 2 & 2 & Al & $\mathrm{B}$ & 117 \\
\hline 10 & Necropsy tissue & 14 & 1 & Al & A & 055 \\
\hline 11 & Laparotomy & 14 & 1 & A1 & A & 055 \\
\hline 12 & Blood culture & 14 & i & $\mathrm{Al}$ & A & 157 \\
\hline 13 & Blood culture & 2 & 2 & $\mathrm{Al}$ & B & 157 \\
\hline 14 & Pleural aspirate & 6 & 1 & A1 & A & 057 \\
\hline 15 & Blood culture & 2 & 1 & $\mathrm{Al}$ & A & 157 \\
\hline 16 & Blood culture & 15 & 1 & $\mathrm{Al}$ & A & 157 \\
\hline 17 & Nurse's hand & 14 & 1 & Al & A & 057 \\
\hline 18 & Nurse's hand & 14 & $i$ & $\mathrm{Al}$ & A & 057 \\
\hline 19 & Vagina & 3 & 1 & Al & A & 157 \\
\hline 20 & Wound & 2 & i & Al & A & 157 \\
\hline 21 & Sputum & 14 & 1 & Al & A & 557 \\
\hline 22 & Wound & 2 & 1 & Al & A & 057 \\
\hline 23 & Urine & 2 & 2 & $\mathrm{Al}$ & A & 057 \\
\hline 24 & Urine & 14 & 1 & $\mathrm{Al}$ & A & 057 \\
\hline 25 & Vagina & 6 & 3 & $\mathrm{Al}$ & A & 157 \\
\hline 26 & Wound & 11 & 2 & $\mathrm{Al}$ & A & 157 \\
\hline
\end{tabular}

TABLE IV - Typing results of the four further outbreaks

\begin{tabular}{lccccc}
\hline & No of patients & DNA type & Immunoblot type & Morphotype \\
\hline The London Hospital (second outbreak) & 8 & 16 & 17 & $\mathrm{Al}$ \\
St Helier Hospital, Carshalton & 4 & 10 & 17 & $\mathrm{Al}$ \\
Queen Elizabeth Hospital, Birmingham & 6 & 4 & $17 \mathbf{a}^{\star}$ & $\mathrm{A4}$ \\
King's College Hospital, London & 3 & 2 & 2 & $\mathrm{~A} 3 / \mathrm{Al}$
\end{tabular}

^Type 17 a differed from type 17 in having single rather than double band at $63 \mathrm{kd}$; this was not enough to classify type as distinct with immunoblot fingerprinting. any laboratory with the basic equipment for DNA recombinant technology.

DNA fingerprinting was first applied to yeasts by Scherer and Stevens, who examined 17 isolates of C albicans." They described four intense bands similar in position to four of the six bands found in our series. Variations in these bands formed the basis of 16 distinct types (table I). Because of the high level of reproducibility and stability of DNA fingerprinting large scale epidemiological studies are feasible. This was not possible with immunoblot fingerprinting because gel to gel variation occurred so that isolates could be compared only when run on the same gel. ${ }^{5}$ Three antigenic band differences were required confidently to distinguish between two isolates by immunoblot fingerprinting, whereas a single difference in one of the intense bands was significant in DNA fingerprinting.

When non-outbreak isolates are typed a predominant strain emerges, whether typed by morphotyping $(90 \%$ are $\mathrm{Al}),{ }^{10}$ immunoblot fingerprinting $(43 \%$ are type 2$), 5$ or DNA fingerprinting (63\% are type 2$)$. These typing systems do not correlate exactly, so that combining typing systems may increase discrimination. It might be possible to increase the discrimination of DNA fingerprinting by using a range of different restriction endonucleases or hybridising fragments against a DNA probe. This, however, would increase the complexity of the technique and the time taken for results to become available.

When DNA fingerprinting was applied to the first London Hospital outbreak it confirmed the existence of an outbreak due to an unusual DNA fingerprint type (DNA type 14; table III). There was variation in the biotype, which could be 055,157 , or 057 , but not in the DNA type or the immunoblot type. Previously morphotyping, serotyping, and biotyping had to be combined to achieve adequate discrimination. ${ }^{3}$ This was unnecessary for DNA fingerprinting, as the outbreak strain could easily be identified by the presence of an unusual combination of three bands in the $2 \cdot 3,2 \cdot 4$, and $1.9 \mathrm{~kb}$ region (fig 3). DNA fingerprinting had a higher degree of discrimination than any of the other typing methods applied to the outbreak and showed that no further cases of systemic candidiasis due to the outbreak strain occurred after the introduction of cross infection control measures and prophylaxis with ketoconazole. Previously, several late cases of systemic candidiasis (cases 14-16; table III) were incorrectly thought to be due to the outbreak strain but DNA fingerprinting showed these three strains to be different.

DNA fingerprinting confirmed that two further patients were colonised by the outbreak strain, and it was possible to isolate the strain from the hands of nurses (table III). This is probably the means of spread between patients and staff and patients and patients. Hence it was possible to contain further episodes of nosocomial systemic candidiasis by strict cross infection control measures and changes in hand disinfectants. ${ }^{24}$

Previous work suggested that particular strains of $C$ albicans were more virulent and likely to cause cross infection, as three of the five outbreaks were caused by strains with a very similar immunoblot fingerprint (types 17 and 17a). ${ }^{4}$ DNA fingerprinting militated against this, as all five outbreak strains were clearly distinguishable from each other. All outbreaks occurred in clinical settings in which patients were predisposed to develop systemic candidiasis - that is, they were immunocompromised, were receiving broad spectrum antibiotics, or had had major bowel surgery. In some cases there was evidence of a lapse in cross infection control. It is this more than the virulence of a particular strain of $C$ albicans which seems to lead to 
outbreaks of nosocomial systemic candidiasis. This explains the comparative ease with which simple measures such as changes in handwashing reagents and implementation of strict cross infection control led to containment of the outbreaks. DNA fingerprinting provides a rapid, reliable means of identifying such outbreaks so that further cases can be prevented.

We thank the Wellcome Trust for financial support, Professor S Tabaqchali, and The London Hospital; King's College Hospital, London; Queen Elizabeth Hospital, Birmingham; and St Helier Hospital, Carshalton, for sending us isolates.

1 Gold JWM. Opportunistic fungal infections in patients with neoplastic disease. $A m \mathcal{F}$ Med 1984;76:458-63.

Burnie JP, Lee W, Williams JD, Matthews RC, Odds FC. Control of an outbreak of systemic Candida albicans. Br Med f 1985;291: 1092-3.
3 Burnie JP, Odds FC, Lee W, Webster C, Williams JD. Outbreak of systemic Candida albicans in intensive care unit caused by cross-infection. Br Med $1985 ; 290: 746-8$.

+ Burnie JP, Matthews R, Lee W, et al. Four outbreaks of nosocomial systemic candidiasis. Epidemiology and Infection 1987:99:201-11.

Le W Burnie J, Marthews R. Fingerprinting Candida albicans. I Immund Methods 1986:93:177-82.

Kellyods 1986;93:177-82.

Kelly KF, Haites NE, Johnston AW. How to start a DNA diagnostic service. BrMed $1988,297: 276-8$

Maniatis T, Fritsch EF, Sambrook J. Molecular cloning: a laboratory manual. Cold Spring Harbor, New York: Cold Spring Harbor Laboratory Press, 1982.

8 Hasenclever HF, Mitchell WO. Antigenic studies of candida I. Observation of two antigenic groups in Candida albicans. F Bacteriol 1961;82:570-3.

9 Odds $\mathrm{FC}$, Abbot $\mathrm{AB}$. A simple system for the presumptive identification of Candida albicans and differentiation of strains within the species. Sabouraudia 1980;18:301-17.

10 Brown-Thomsen J. Variability in Candida albicans (Robin) Berkhout. Studies on morphology and biochemical activity. Hereditas 1968;60:335-98.

11 Scherer S, Stevens DA. Application of DNA typing methods to epidemiolog and taxonomy of Candida species. 7 Clin Microbiol 1987;25:675-9.

(Accepted 2 December 1988

\title{
Prevalence of spina bifida occulta in patients with functional disorders of the lower urinary tract and its relation to urodynamic and neurophysiological measurements
}

\author{
A Fidas, H L MacDonald, R A Elton, A McInnes, S R Wild, G D Chisholm
}

Western General Hospital, Edinburgh

A Fidas, $\mathrm{MD}$, urological registrar

A McInnes, MRCP, consultant neurophysiologist

S R Wild, FRCR, consultant

radiologist

G D Chisholm, FRCSED,

professor of surgery

Eastern General Hospital, Edinburgh

H L MacDonald, FRCR, consultant radiologist

Medical Statistics Unit, University of Edinburgh

R A Elton, PHD, senior

lecturer

Correspondence and requests for reprints to:

Professor G D Chisholm,

Department of Urology,

Western General Hospital,

Edinburgh EH4 2XU.

Br.Med f 1989;298:357-9
Abstract

Objective-To determine the relation between neurophysiological abnormalities and the radiological detection of spina bifida occulta in patients with dysfunction of the lower urinary tract.

Design-Blind assessment and subsequent decoding of mixed batch of abdominal radiographs from patients with and without urological symptoms for evidence of spina bifida occulta and comparison of results with those of previous control series.

Setting-Review study among tertiary referrals to an incontinence clinic of a city hospital.

Patients-One hundred and thirty eight adults with proved urodynamic abnormalities in whom neurophysiological measurements were available.

Interventions - None.

End point-Correlation of neurophysiological abnormalities in lower urinary tract dysfunction with presence and type of spina bifida occulta and level of opening of posterior sacral arcs.

Measurements and main results-On decoding radiographs those from patients without urological symptoms showed a similar prevalence of spina bifida occulta to that in the control series $(631 / 2707$ controls; $23 \%$ ). By contrast, patients with urological symptoms had a significantly increased prevalence of spina bifida occulta at $S 1$ and $S 2$ and a higher level of opening of posterior sacral arcs. The increased prevalence of the bony defect was particularly striking in men with urgency and instability and in women with stress incontinence. No significant correlation was found between any particular neurophysiological abnormality and the presence of spina bifida.

Conclusions - In patients with dysfunction of the lower urinary tract neurophysiological abnormalities may be associated with congenital dysraphic lesions in the lower lumbar spine and sacrum. There appears to be no direct causal relation between the radiological and neurophysiological abnormalities but the findings suggest a common aetiological factor.

\section{Introduction}

Spina bifida occulta in the lower lumbar spine and sacrum is generally considered to be unimportant clinically, ' - and similarly a high opening of the posterior sacral arcs is described as a normal variant. ${ }^{3}$ Bony defects in the sacrum may be associated with fibrous bands or with fatty or other tumours occupying the laminal defect. This may result in compression of the nerves of the cauda equina $a^{+\cdot b}$ and interfere with nerve conduction in the sacral reflex arcs.

In 1985 Galloway and Tainsh found an increased prevalence of spina bifida occulta in a small group of adults with lower urinary tract problems.? We therefore decided to correlate the functional disorders previously reported from this department ${ }^{8}$ with the presence of spina bifida occulta. Plain radiographs of the renal tracts (kidney, ureter, and bladder films) from 138 patients were reviewed and the presence and type of spina bifida occulta and level of opening of the posterior sacral arcs noted. These findings were correlated with the results of the urodynamic and neurophysiological studies.

\section{Patients and methods}

Plain abdominal radiographs were available from 138 out of 180 consecutive adult patients attending an incontinence clinic, and these 138 patients form the basis of our study. All the patients had received the usual urological and radiological assessments and in addition had been the subject of urodynamic studies and neurophysiological measurements, as described. ${ }^{9}$ The results of the urodynamic and neurophysiological investigations have been reported. ${ }^{x}$ The presence of spina bifida occulta and the upper level of sacral arc opening were assessed from the kidney, ureter, and bladder films. The patients were grouped for analysis by sex, as in a control study of a genetically similar population of over 2700 normal adults we found spina bifida occulta to be twice as common in men $(30 \%)$ as in women $(17 \%) .^{10}$ In order to eliminate bias the films were mixed with an equal number of abdominal radiographs taken at the same hospital from patients without urological symptoms and all films were assessed together by the same observers. When the films were decoded the prevalence of spina bifida occulta found in the patients without symptoms agreed closely with that found in the control study.

The patients were further grouped according to their presenting symptoms, such as frequency or enuresis, 